\title{
Collective Memory: Collaborative and Individual Processes in Remembering
}

\author{
Mary Susan Weldon and Krystal D. Bellinger \\ University of California, Santa Cruz
}

\begin{abstract}
Two experiments compared collaborative and individual recall. In Experiment 1, participants encoded pictures and words with a deep or shallow processing task, then recalled them twice either individually or collaboratively. Collaborative groups recalled more than individuals, but less than nominal groups (pooled individuals), thus exhibiting collaborative inhibition. However, group recall appeared to be more stable over time than individual recall. Groups and individuals both showed a picture-superiority effect, a level-of-processing effect, and hypermnesia. In Experiment 2, participants recalled the story "War of the Ghosts" (from F. C. Bartlett, 1932), and again collaborative groups recalled more than individuals, but less than nominal groups. Both the individual and collaborative recalls were highly organized. There was evidence that the collaborative groups tended to rely on the best individual to a greater extent in story than in list recall. Possible social and cognitive mechanisms are considered.
\end{abstract}

Several years ago, at a typical faculty meeting at an unnamed university, a good bit of time was devoted to trying to figure out what had been accomplished at the previous meeting. There often seemed to be considerable disagreement about what had been accomplished, and various individuals collaborated to try to reconstruct an account. From the point of view of a memory researcher, the situation presented interesting questions about the nature of collective memory as compared with individual memory. There were obvious similarities between the group processes and wellknown properties of individual recall (e.g., reconstruction), but a variety of other issues came to mind. Are there important differences between group and individual memory? What impact does the individual have on the group, and the group on the individual? Does the social setting affect what is remembered and how it is remembered?

Traditionally, mainstream experimental psychology has characterized cognitive mechanisms as processes taking place within the individual mind. A person is isolated in a laboratory relatively free from distractions and is asked to perform various tasks that tap into the individual's cognitive processes. An issue that seems to have been largely ignored, however, is the social nature of cognitive activity, which is the topic of interest here. Rather than viewing the social milieu as contamination, it could be fruitful to view it as a fundamental constituent of cognition. We refer to this

Mary Susan Weldon and Krystal D. Bellinger, Department of Psychology, University of California, Santa Cruz.

This research was supported by grants from the Division of Social Sciences and a Faculty Research Grant from the University of California, Santa Cruz. We thank Barbara Basden and David Basden for their interest and insights into this work.

Correspondence concerning this article should be addressed to Mary Susan Weldon, Department of Psychology, University of California, Santa Cruz, Santa Cruz, California 95064. Electronic mail may be sent via Internet to weldon@ @ats.ucsc.edu. general endeavor in memory research as the study of collective memory.

\section{Dimensions of Collective Memory}

Memory is social in multiple ways, and so collective memory can be conceptualized in a variety of ways. First, and most obviously, remembering may take place as a social activity. People can collaborate to recall events, such that group memory is an emergent property of different individuals' recollections expressed within a social context. In this situation, the social context exerts its influence at several levels. For example, the social setting suggests a particular group identity and connotes particular goals and norms that guide the process and content of retrieval. As an example, a teenager might provide one account of last night's party to his or her parents, but the process of recollection and the account that is produced will likely be quite different when this same teen is reminiscing about the party with his or her friends. Across different situations, the social setting (a) prescribes the style and contents of recall that are appropriate in the setting, (b) is characterized by social dynamics that govern who speaks when and whose recollections receive the most weight, and (c) varies in the purpose of the recollective activity (e.g., assuring mom and dad they have nothing to worry about vs. cultivating peer relationships). Thus, the properties of the social setting will influence how past events are reconstructed.

Although performance on traditional memory tests is typically interpreted on the assumption that the goal of remembering is to retrieve items as accurately and quickly as possible, remembering more typically takes place in the service of other tasks. For example, people often reminisce to establish social relations or common ground. In these situations, the speed and accuracy of retrieval might be less important than developing positive social relationships, and thus accuracy may be sacrificed for camaraderie; or to 
maintain status in a group, accuracy may be sacrificed for persuasiveness. In storytelling, accuracy may be sacrificed for dramatic effect, and in work groups that are assembled to accomplish tasks such as decision making, product design, problem solving, and so forth, memory may operate to support the tasks and guide decisions, but may not serve as the goal of the group activity per se. Therefore, as a social process, remembering may exhibit many interesting properties that are overlooked when it is studied as an individual cognitive activity.

A second way in which remembering is social is in the sense that it is situated within a larger culture or group which, in the practice of its activities, teaches its members to use memory in a particular way. Bartlett (1932) addressed this aspect of the social nature of memory in his book Remembering: A Study in Experimental and Social Psychology. He argued that social groups are organized units with tendencies and characteristics that exist only as the group exists and disappear if the group dissolves. Thus, group characteristics are something different from a simple sum of the individual characteristics, and social groups have emergent properties that may affect remembering in the group. The interests and characteristics of the group may exist as schemata that bias members' attention to and reconstruction of events. Bartlett asserted that "both the manner and the matter of recall are often predominantly determined by social influences" (p. 244). Consistent with this idea, cross-cultural studies demonstrate that the content and process of recall differ across cultures (see review by Rogoff \& Mistry, 1985).

A third way in which memory may be considered to be social concerns the manner in which information is represented in a group. Information may be shared collectively among all of the individuals in a group such that each person possesses knowledge in common, or alternatively, information may be distributed or divided among individuals. Wegner, Giuliano, and Hertel (1985) have discussed the possibility that group processes may result in shared memories that are different from individual memories (cf. Meudell, Hitch, \& Kirby, 1992). Thus, collective memory may have emergent properties that are not predictable from individuals alone. Furthermore, the distinction between shared and distributed memory is meaningful because the dynamics of retrieval may be very different for these two types of collective representation.

Finally, collective memory has important social, cultural, and political implications because it affects people's perceptions of individuals, groups, and events, and has consequences for actions and reactions toward them. Shared memories have a significant impact on the construction and communication of events, interpersonal relations, group histories, and government and social policy, as well as the characterization of groups and institutions. An interesting example of this dynamic occurred in recent history. When former President Bush and the Congress declared war in the Persian Gulf, it was commonly agreed that we did not want "another Vietnam." The collective memory of the Vietnam War was invoked in a specific way to win support for military strategy in the Persian Gulf.
A variety of other perspectives on the social nature of memory and the conceptualization of collective memory are possible (e.g., see Bartlett, 1932; Clark \& Stephenson, 1989; Durkheim, 1915; Halbwachs, 1950/1980; Jung, 1953; Rogoff \& Mistry, 1985; Vygotsky, 1962, 1978; Wundt, 1910/1916), but for the moment the main point is that the stady of collective memory may yield insights into individual and group cognitive processes about which little is known at present. Many interesting questions need to be addressed. What impact does individual remembering have on group remembering, and vice versa? What are the emergent properties of group remembering? How are shared memories established? When multiple accounts of a situation are possible, who or what determines the emergence of the majority memory? How is historical memory different from memory for experienced events? How can social and cultural factors be accounted for in the description of group memory? What are the appropriate units of analysis, the individuals within the sociocultural context, or the activity itself defined by the tasks, goals, and sociocultural setting? In the work reported here, we begin to investigate this domain in a modest fashion and address only a small number of the issues that arise when considering memory as a social phenomenon.

\section{Collaborative and Individual Recall}

The goal of these experiments was to explore three main questions. First, are groups or individuals more productive in terms of how much they remember? Second, does group remembering obey principles similar to individual remembering? Third, what is the influence of group recall on individual recall, and vice versa? To address these issues, two experiments were conducted. In Experiment 1, groups of 3 individuals studied mixed lists of pictures and words with either a shallow or a deep processing task. Participants then recalled the items twice, either individually-individually (II), collaboratively-collaboratively (CC), individuallycollaboratively (IC), or collaboratively-individually (CI). In Experiment 2, groups of 3 people heard two readings of the story "War of the Ghosts" (from Bartlett, 1932; see Appendix) and then recalled the story in one of the four conditions (II, CC, IC, or Cl).

With respect to the question of group productivity, some studies of group versus individual recall have been reported in the literature. For example, it is commonly believed that "two heads are better than one," and research indicates that when people collaborate to recall an event the group does remember more than individuals working alone (e.g., Clark, Stephenson, \& Kniveton, 1990; Dashiell, 1935; Hoppe, 1962; Lorge \& Solomon, 1961; Stephenson, Brandstätter, \& Wagner, 1983; Yuker, 1955). However, the question arises as to whether group recall is better than, equal to, or worse than the sum of the individual recalls. On the one hand, it is possible that information recalled by others in the group may provide cues to help individuals remember items that they would not recall if working alone, a process called crosscuing (Meudell et al., 1992; Meudell, Hitch, \& Boyle, 1995). On the other hand, collaborative recall may result in process 
loss such that the interacting group suffers a decrement. For example, the group activity may interfere with individual performance, or some individuals may slack off in the group. To assess productivity, one can compare the performance of a collaborating group with performance in a nominal group, the latter created by pooling the nonredundant responses of individuals working alone (e.g., if Person 1 recalls items $a, b, c, d$, Person 2 recalls $b, c, d, e, f$, and Person 3 recalls $c, f, g$, the nominal group recall is $a, b, c, d, e, f, g$ ).

Many studies of brainstorming report that interacting groups actually produce fewer ideas than nominal groups, indicating that collaboration inhibits productivity (e.g., Bouchard \& Hare, 1970; Taylor, Berry, \& Block, 1958). Therefore, it is possible that in recall, group collaboration likewise has an inhibitory effect such that interacting groups recall less than nominal groups. Some evidence that this might be the case was obtained by Lorge and Solomon (1961), who observed that group learning over multiple trials was overestimated by a model predicting additivity of individual learning rates. One of the goals of the present work was to determine whether collaborative recall facilitates, inhibits, or simply pools individuals' knowledge, and to see whether the effects are consistent across a variety of materials and encoding conditions. We tested people in groups of 3 because there is some evidence that with dyads, nominal and collaborative groups perform equally well (e.g., Meudell et al., 1992, 1995; but also see Andersson \& Rönnberg, 1996), and we wanted a stronger test of the effect of group processes.

A second issue of interest is whether principles of memory derived from research on individuals generalize to collaborative recall. In Experiment 1, we manipulated two variables known to have robust effects in individual remembering: level of processing (Craik \& Lockhart, 1972) and picture versus word encoding. On free recall, deep or meaningful processing produces better recall than shallow or superficial processing (Craik \& Tulving, 1975). Also, pictures are typically recalled better than words, an outcome known as the picture-superiority effect (e.g., Nelson, 1979; Paivio, 1971). We expected to observe these same outcomes with groups. Of course, if these variables had different effects in group and individual recall, it would suggest that collaborative recall is radically different from individual recall, but there is no a priori reason to believe this would happen in the present experiments. Nevertheless, it was deemed important to establish empirically the continuity between individual and collaborative recall for these standard, robust variables. Unique properties of collaborative recall are likely to be of a more subtle nature, so we included analyses of the organization of the material, intertest reminiscence and forgetting, and intrusion rates to see if the groups and individuals exhibited differences on these measures.

A third goal of this work was to investigate how individual recall affects group recall, and vice versa. There is evidence that individual recall benefits from prior collaborative recall (e.g., Stephenson \& Wagner, 1989; Yuker, 1955), but that work compares a single individual-recall trial with individual recall preceded by group discussion or group recall. Therefore, it does not enable one to distinguish between the effects of prior group recall and possible effects of hypermnesia, the increased recall that occurs when multiple recall trials follow in immediate succession (Erdelyi \& Kleinbard, 1978; Payne, 1987). Our design disentangles these factors and also assesses the effect of prior individual recall on subsequent group recall.

In summary, the goal of this research was to investigate and compare memory as both an individual and a social process, specifically to study productivity, reciprocal influence, and the generalizability of certain principles of memory.

\section{Experiment 1}

\section{Method}

Participants and design. One hundred ninety-two undergraduates from the University of California, Santa Cruz, participated for credit in lower division psychology courses. Participants were tested in groups of 3.

Two encoding variables were manipulated within subjects: stimulus form (pictures vs. words) and level of processing (deep vs. shallow). During the test, participants recalled the items twice, creating an additional within-subjects variable (first recall vs. second recall). Each recall was either individual or collaborative, and participants served in one of four different test conditions representing the four possible combinations (II, CC, IC, and CI). There were 16 three-person groups in each test condition.

Materials. Target items were $\mathbf{4 0}$ common items (e.g., grapes, snowman, hammer, sailboat) selected from Snodgrass and Vanderwart's (1980) picture norms. Two slides were obtained for each item, one containing the black-and-white line drawing from Snodgrass and Vanderwart's norms and the other containing the word typed in lowercase Arial font.

The items were randomly divided into four sets that were counterbalanced so that each appeared an equal number of times in each study condition (picture-shallow, word-shallow, picturedeep, word-deep) across participants and test conditions. Eight additional pictures and eight words were selected to serve as buffer items in the study lists.

For the study phase, two blocks of targets were created by assigning two sets of items to one block and two to the other block. In each block, one item set was designated as pictures and one as words, with this designation counterbalanced across subjects. Pictures and words were randomly mixed in the block with the restriction that no more than three pictures or words appeared in succession. Half the participants studied one item block with the deep-encoding task and the other item block with the shallow task, with the assignment of encoding task to item block counterbalanced across subjects. The order of the encoding task was also counterbalanced such that half the participants performed the deep task and half the shallow task first. Buffer items were divided so that there were 2 pictures and 2 words at the beginning and end of both blocks. Thus, each block contained 28 items ( 10 pictures, 10 words, and 8 buffers).

Procedure. Participants were tested in groups of 3. They were told that they would perform tasks related to research on problem solving, but they were not told that they would receive a memory test or work in groups. (Incidental learning was used to avoid the risk that intentional learning would elevate performance in the shallow-processing condition.) They were given a rating sheet for the study phase and received appropriate instructions before each block of slides. For the shallow-encoding task, they rated the graphic quality of each picture and word (whether it was crisp, clear, easy to view) on a scale of 1 to 5 (poor to high quality). Slides 
Table 1

Experiment 1: Proportion of Correct Free Recall as a Function of Stimulus Type, Level of Processing, Group Size, and Recall Order

\begin{tabular}{|c|c|c|c|c|c|}
\hline \multirow[b]{3}{*}{$\begin{array}{l}\text { Recall condition } \\
\text { (test condition) }\end{array}$} & \multicolumn{5}{|c|}{ Encoding condition and rating task } \\
\hline & \multicolumn{2}{|c|}{ Words } & \multicolumn{2}{|c|}{ Pictures } & \multirow[b]{2}{*}{$M$} \\
\hline & $\begin{array}{l}\text { Graphic } \\
\text { quality }\end{array}$ & Pleasantness & $\begin{array}{l}\text { Graphic } \\
\text { quality }\end{array}$ & Pleasantness & \\
\hline \multicolumn{6}{|l|}{ Individual recall } \\
\hline First recall (II) & .11 & .31 & .26 & .41 & .27 \\
\hline \multicolumn{6}{|l|}{ Second recall } \\
\hline Preceded by individual recall (II) & .10 & .36 & .30 & .43 & .30 \\
\hline Preceded by collaborative recall (CI) & .14 & .46 & .45 & .53 & .40 \\
\hline \multicolumn{6}{|l|}{ Nominal-group recall } \\
\hline First recall (II) & .27 & .64 & .53 & .78 & .56 \\
\hline \multicolumn{6}{|l|}{ Second recall } \\
\hline Preceded by individual recall (II) & .26 & .71 & .56 & .81 & .59 \\
\hline Preceded by collaborative recall (CI) & .23 & .66 & .64 & .75 & .57 \\
\hline \multicolumn{6}{|l|}{ Collaborative group recall } \\
\hline First recall $(\mathbf{C C})$ & .21 & .53 & .53 & .61 & .47 \\
\hline \multicolumn{6}{|l|}{ Second recall } \\
\hline Preceded by individual recall (IC) & .20 & .61 & .67 & .70 & .54 \\
\hline Preceded by collaborative recall (CC) & .22 & .59 & .54 & .63 & .49 \\
\hline
\end{tabular}

Note. Test conditions (in parentheses) indicate the source of the data, with the bold letter indicating the recall trial. II = individual-individual; $\mathbf{C I}=$ collaborative-individual; $\mathbf{C C}=$ collaborativecollaborative; IC $=$ individual-collaborative.

were not designed to vary on this dimension; people responded to natural variations in quality. For the deep-encoding task, participants rated how pleasant they thought the real-world item designated by each picture and word was, with a scale of 1 to 5 (very unpleasant to very pleasant). Participants circled a number on their rating sheet for each item. Slides were presented for $6 \mathrm{~s}$ each. As a distractor task after the encoding phase, each person worked alone for $5 \mathrm{~min}$ to solve a set of mazes.

Next, the participants received two recall trials, the task and order depending on the test condition (II, CC, IC, or CI). In the individual recall task, each person received a blank sheet of paper and was instructed to write down as many of the pictures and words as he or she could remember from both study tasks (deep and shallow). In the collaborative recall task, participants were told they would work together as a group to recall as many items as possible. One person was asked to serve as the recorder for the group and to write down everything the members recalled, as well as to participate in the collaborative recall. Participants were given no instructions about how to resolve disagreements and were allowed to resolve them as they saw fit. In each condition, participants were given $7 \mathrm{~min}$ to recall as many items as possible. After the first recall, the answer sheets were removed and the participants were immediately given instructions for the second recall, which was either collaborative or individual. At the end of the experiment, they completed a brief questionnaire and were debriefed.

\section{Results}

The proportions of items correctly recalled in each condition are presented in Table 1 . The individual recall data were scored in two ways. First, the total number of items each individual recalled was computed for each participant, and the means are labeled as "Individual Recall." Second, the recalls of the 3 individuals were pooled, with redundant items counted only once, and these means are designated as "Nominal Group Recall." The data for the collaborative groups were scored by counting the total number of nonredundant items recalled by the group and are labeled as "Collaborative Group Recall." Some aspects of the data are summarized in Figures 1 and 2.

The individual, nominal, and collaborative conditions could not all be compared in the same analysis because the individual and nominal conditions contained the same participants, whereas the nominal and collaborative conditions contained different participants. Different comparisons were conducted to answer each of the research questions, and the conditions that contributed the data used in each analysis are noted in turn. Significant results are reported at $p<.05$.

Differences in productivity. To determine whether the level of recall differed across conditions, two different analyses were conducted. One compared collaborative with individual recall by using the individual data (CC vs. II-ind, where II-ind refers to participants tested individually and scored individually), and the other compared collaborative with nominal recall by using the individuals' pooled data (CC vs. II-nom, where II-nom refers to participants who were tested individually but had their responses pooled). Figure 1 summarizes the differences in productivity, collapsed across level of processing and stimulus form.

The question of whether groups recalled more than individuals was addressed by comparing condition $\mathrm{CC}$ with II-ind in a $2 \times 2 \times 2 \times 2$ mixed analysis of variance (ANOVA), with recall condition (individual vs. collaborative) as the between-subjects variable and with recall trial (first vs. second), level of processing (deep vs. shallow), and stimulus form (picture vs. word) as within-subjects variables. Proportion of correct recall was significantly higher in collaborative groups $(M=.48)$ than in individuals $(M=.28)$, $F(1,62)=85.66, M S E=0.044$. This finding replicates 


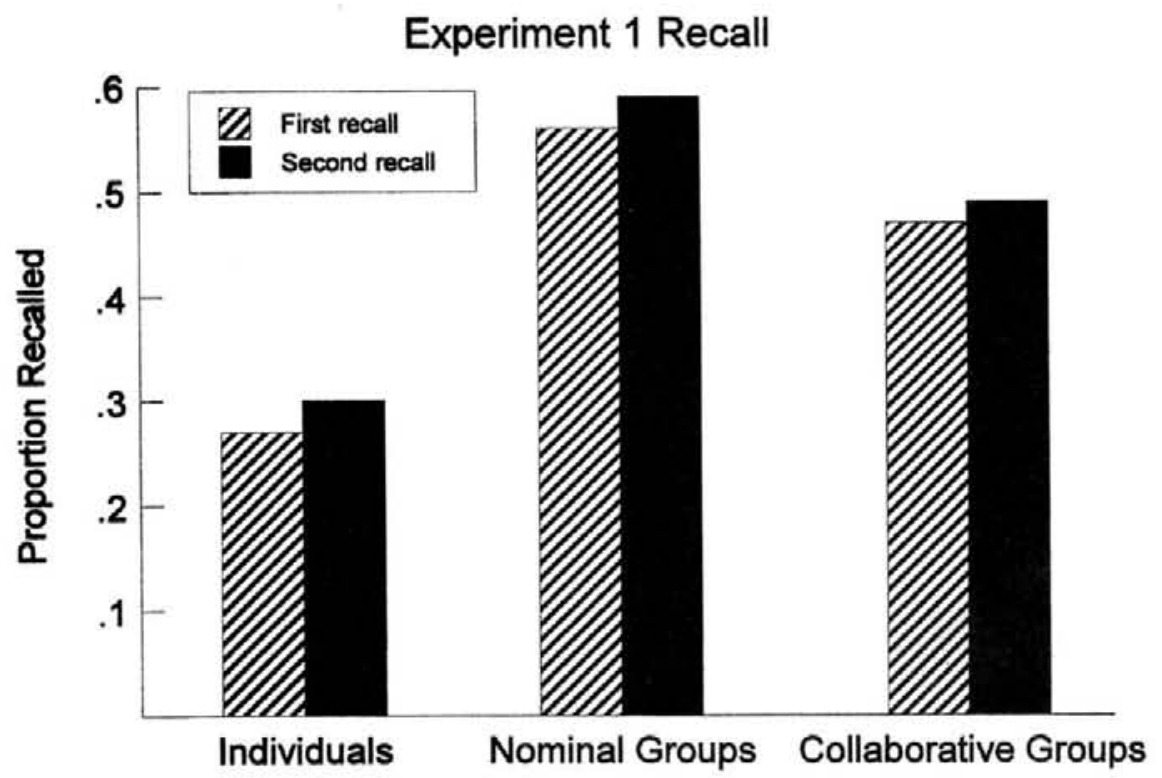

Figure 1. Recall on the first and second recall trials in Experiment 1. Data for the individuals and the nominal groups are from recall condition II. Data for the collaborative groups are from recall condition $\mathrm{CC}$. II = individual-individual $\mathbf{C C}=$ collaborative-collaborative.

others in the literature and was as expected. (Other aspects of this analysis are discussed later.)

In the analysis comparing all of the individuals with the collaborative groups, the numbers of observations in the two conditions were very uneven: There were 48 individuals and 16 groups. Therefore, a second analysis was conducted by taking the best individual from each of the 16 sets of 3 individuals and comparing their average performance with

\section{Experiment 1 Recall}

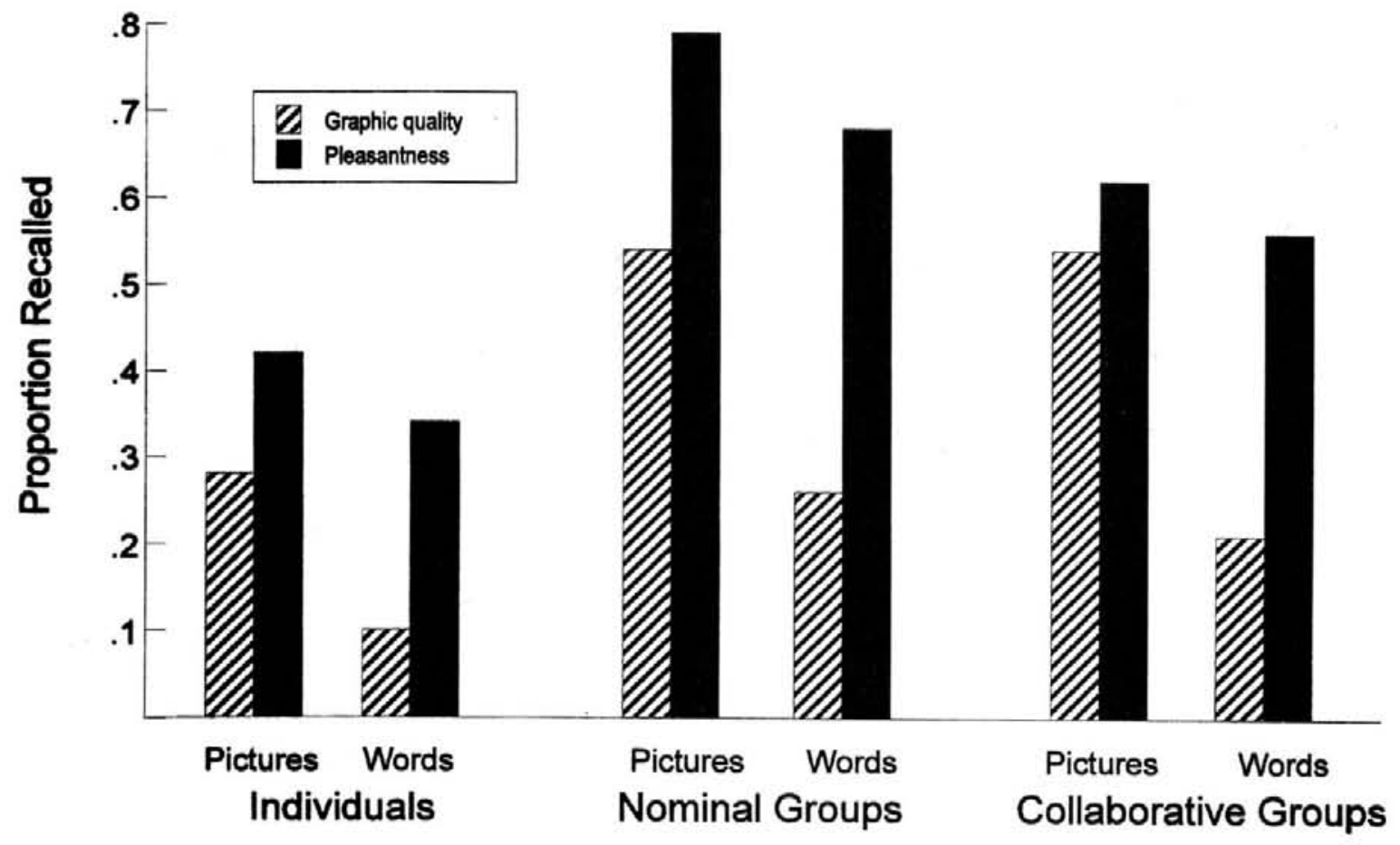

Figure 2. Free recall in Experiment 1. Data are averaged across first and second recalls. Data for the individuals and the nominal groups are taken from recall condition II. Data for the collaborative groups are taken from recall condition CC. II = individual-individual; $\mathrm{CC}=$ collaborative-collaborative. 
that of the collaborative groups. The collaborative groups $(M=.48)$ still recalled significantly more than the best individuals $(M=.36), F(1,30)=31.56, M S E=0.004$. These results show that the collaborative group was not simply relying on the best individual in the group, that is, the best individual did not represent the upper bound of group performance.

Of most interest was the comparison between the nominal and collaborative groups. A $2 \times 2 \times 2 \times 2$ mixed ANOVA (variables: recall condition, recall trial, level of processing, stimulus form) was conducted comparing the II-nom condition with the CC condition. For II-nom, the individuals' pooled data were used. The ANOVA revealed that nominal groups $(M=.57)$ recalled more than collaborative groups $(M=.48), F(1,30)=10.64, M S E=0.045$ (see Figure 1).

The data reveal that although collaborative groups recalled more than individuals, collaboration did not optimize individual recall. In other words, when working together in a group to recall information, individuals recalled less than when they worked alone. We refer to this effect as collaborative inhibition.

Level-of-processing and picture-superiority effects. One of the objectives of this study was to see whether two robust principles of individual remembering generalize to collaborative remembering. Figure 2 displays the effects of level of processing and stimulus type for individual and collaborative recall. (The data for the nominal group are included in the figure for completeness, but were not included in this analysis because the goal was to evaluate the effects of collaboration.) The $2 \times 2 \times 2 \times 2$ ANOVA comparing individual with collaborative recall (II-ind vs. CC) revealed a significant level-of-processing effect, $F(1,62)=40.19$, $M S E=0.097$, with deep processing $(M=.43)$ producing better recall than shallow processing $(M=.22)$. There was also a significant picture-superiority effect, $F(1,62)=$ $69.15, M S E=0.035$, with pictures $(M=.41)$ recalled better than words $(M=.26)$. There was a significant interaction between stimulus form and level of processing, $F(1,62)=$ $20.30, M S E=0.038$, such that the advantage of pictures over words was diminished with the deep level of processing (see similar findings in D'Agostino, O'Neill, \& Paivio, 1977; Durso \& Johnson, 1980; Weldon \& Coyote, 1996).

Neither level of processing nor stimulus form entered into a significant two-way interaction with recall condition (individual vs. collaborative), which suggests that these variables operated in a similar fashion in both individual and collaborative recall. However, there was a significant threeway interaction among level of processing, stimulus form, and group type (individual vs. collaborative), $F(1,62)=$ 4.56, $M S E=0.038$, due to the fact that the picturesuperiority effect under graphic-encoding conditions was somewhat larger in collaborative recall than in individual recall. Thus, the picture-superiority effect was somewhat exaggerated in collaborative groups under conditions of shallow coding.

With respect to the encoding variables tested here, individual and collaborative recall revealed similar principles of memory. Specifically, deep processing produced better recall than shallow processing; pictures were recalled better than words; and the picture-superiority effect diminished under deep-encoding conditions. These findings suggest that even though collaborative recall is not the sum of the individual recalls, it is still largely a product of individual recall. This outcome is not surprising, but it is not demanded. For example, it is conceivable that collective processes would engender unique strategies that would enable the group to overcome the limitations of relatively poor encoding conditions like the shallow encoding of words. For instance, people may be able to cross-cue each other and improve access to the material (Meudell et al., 1995), which could benefit poorly remembered classes of items to a greater degree than well-remembered classes. However, there is no evidence for such an effect in our data. The collaborative inhibition is consistent with Meudell et al.'s (1995) failure to observe cross-cuing and with Andersson and Rönnberg's (1996) evidence of impaired performance in dyad recall. Furthermore, the exaggerated advantage of pictures over words in the shallow-encoding condition suggests that the groups were unable to develop a strategy to overcome the mnemonic deficit commonly observed for shallowly processed words.

Item intrusions. One question that arises is whether groups are more or less susceptible to the intrusion of false memories. The average number of item intrusions for individual and collaborative recall, on both the first and second recalls, is presented in Table 2. Overall, the intrusion rates were very low, as is typical in free recall (e.g., Payne, 1986, Experiment 4). A $2 \times 2$ ANOVA evaluating recall condition (II vs. CC) and recall trial (first vs. second) revealed that there were significantly more intrusions on the second recall $(M=1.94)$ than on the first recall $(M=1.36)$, $F(1,62)=10.53, M S E=13.13$. Although there was a trend toward higher intrusion rates in the collaborative groups, the effect was not significant, $F(1,62)=1.63, M S E=11.00$, $p=.21$. Finally, the trend toward a larger intertrial increase in intrusion rates in the collaborative groups than in the individual recall condition was not significant, $F(1,62)=$ $2.01, M S E=2.50, p=.16$.

Vollrath, Sheppard, Hinsz, and Davis (1989) have suggested that groups have better error-checking strategies than individuals and so are likely to produce fewer incorrect responses. They required their groups to reach unanimous consensus and observed that trends for intrusions, false alarms, and misses were slightly lower in collaborating groups. However, Basden, Basden, Bryner, and Thomas (1997) did not require groups to reach consensus and found intrusions to be higher in collaborative groups. They suggested that when groups are not required to reach consensus,

Table 2

Experiment 1: Intrusion Rates, Expressed as the Number of Nontarget Items Produced

\begin{tabular}{lcc}
\hline \multicolumn{1}{c}{ Type of recall } & First recall & Second recall \\
\hline Individual (II) & 1.27 & 1.69 \\
Collaborative (CC) & 1.63 & 2.69 \\
\hline
\end{tabular}

Note. II $=$ individual-individual recall; $\mathrm{CC}=$ collaborativecollaborative recall. 
intrusions are less likely to be edited out. Consistent with this, we did not require our groups to reach consensus, and our results are similar to Basden et al.'s (but see Ravicchio et al., 1996).

Hypermnesia, reminiscence, and forgetting. One interesting pattern in the data that was not predicted a priori is hypermnesia, or increased recall from the first to second recall trials (see Figure 1). An ANOVA comparing collaborative with individual recall revealed a significant main effect of recall trial, $F(1,62)=11.44, M S E=0.005$, and no interaction with recall condition $(F<1)$, indicating that recall improved to about the same degree in collaborative (proportion correct for the first recall trial, $M=.47$; for the second, $M=.49$ ) and individual (for the first recall trial, $M=.27$; for the second, $M=.30$ ) recall. The hypermnesia effect is small but reliable. In experiments designed to study hypermnesia, participants are typically instructed to rerecall items from the first test and to try particularly to recall items they had not recalled on the first test, which produces larger hypermnesia effects (e.g., Payne, 1986). We did not include such instructions because we were not looking for hypermnesia, but we still obtained a significant, albeit small, effect. Our results are consistent with those of Meudell et al. (1995), who found that dyads and individuals both exhibited hypermnesia. They also suggested that if collaboration facilitates recall, then the dyads should exhibit more hypermnesia than individuals, which they did not. This is consistent with the idea that collaboration introduces inhibitory processes that impair recall.

We examined whether patterns of interest reminiscence and forgetting differed for individuals, nominal groups, and collaborative groups. Reminiscence was defined as an item not retrieved on Recall 1 but retrieved on Recall 2, and forgetting was defined as an item retrieved on Recall 1 but not retrieved on Recall 2 . Table 3 presents average reminiscence and forgetting, expressed as number of items, in the four encoding conditions for participants in the II and CC recall conditions. The last column presents the total number of items summed across the four encoding conditions.

Overall, reminiscence and forgetting were quite low, but an ANOVA comparing reminiscence and forgetting in individuals and collaborative groups revealed that reminis- cence was significantly higher than forgetting, $F(1,62)=$ 13.32, $M S E=5.39$, which accounts for the hypermnesia effect. There was a tendency for collaborative groups to both reminisce and to forget slightly less than the individuals, suggesting that group performance was more stable or consistent over time. However, the difference between collaborative groups and individuals was not significant for either reminiscence $(t=1.00)$ or forgetting $(t<1.00)$.

We also examined reminiscence and forgetting in the collaborative groups versus the nominal groups and found that the group differences were marginally significant; for intertest reminiscence, $t(30)=1.75, p=.09$, and for intertest forgetting, $t(30)=1.79, p=.10$. Therefore, pooling the individuals' performance exaggerated the apparent instability of the individuals, suggesting that each person tended to remember and forget somewhat different items from one another. However, the trends toward group differences were small and should be viewed as only preliminary and suggestive. The possibility that group performance may have been more stable over time was examined further by looking at subjective organization.

Subjective organization. We attempted to assess whether subjective organization differed in individual and collaborative recall. Two issues can be evaluated by looking at subjective organization. First, collaborative inhibition might have been due to disruption of the individuals' organization of the material; if so, one might expect that collaborative recall would be less organized than individual recall. This interpretation of the collaborative-inhibition effect was suggested by Basden et al. (1997), who obtained collaborative inhibition with large categorized lists and also found less category clustering in collaborative than individual recall. However, we could not address this issue because our lists were composed of unrelated items, and therefore techniques for assessing organization relative to an existing standard were not applicable.

Second, individual performance might have been more stable over time than group performance; if so, then individuals should have maintained a more stable organization of the material from the first to the second recall. To address this, we compared the organization of Recall 2 with that of Recall 1. We used a bidirectional measure of intertrial

Table 3

Experiment 1: Intertest Reminiscence and Forgetting, Expressed in Number of Items

\begin{tabular}{|c|c|c|c|c|c|}
\hline \multirow[b]{3}{*}{ Intertest performance } & \multicolumn{4}{|c|}{ Encoding condition and rating task } & \multirow[b]{3}{*}{$\begin{array}{l}\text { Total } \\
\text { items }\end{array}$} \\
\hline & \multicolumn{2}{|c|}{ Words } & \multicolumn{2}{|c|}{ Pictures } & \\
\hline & $\begin{array}{l}\text { Graphic } \\
\text { quality }\end{array}$ & Pleasantness & $\begin{array}{l}\text { Graphic } \\
\text { quality }\end{array}$ & Pleasantness & \\
\hline \multicolumn{6}{|l|}{ Reminiscence } \\
\hline Individual recall (II) & 0.06 & 0.92 & 0.63 & 0.75 & 2.35 \\
\hline Nominal groups (II) & 0.25 & 1.13 & 0.88 & 0.63 & 2.88 \\
\hline Collaborative groups (CC) & 0.38 & 0.69 & 0.50 & 0.38 & 1.94 \\
\hline \multicolumn{6}{|l|}{ Forgetting } \\
\hline Individual recall (II) & 0.19 & 0.35 & 0.31 & 0.48 & 1.33 \\
\hline Nominal groups (II) & 0.44 & 0.38 & 0.38 & 0.50 & 1.69 \\
\hline Collaborative groups (CC) & 0.69 & 0.25 & 0.31 & 0.25 & 1.06 \\
\hline
\end{tabular}

Note. $\mathrm{II}=$ individual-individual recall; $\mathrm{CC}=$ collaborative-collaborative recall. 
repetitions examining pair frequency $(P F)$, which is the frequency with which the same two items are recalled adjacently on Recall 1 and Recall 2, regardless of order (e.g., camel, balloon and balloon, camel count as an adjacent repetition; Anderson \& Watts, 1969; Sternberg \& Tulving, 1977). $P F$ is computed as

$$
P F=O(I T R 2)-E(I T R 2)=O(I T R 2)-\frac{2 c(c-1)}{h k},
$$

where $O(I T R 2)$ represents the number of pairs of items recalled on Trials $t$ and $t+1$ in adjacent positions; $E(I T R 2)$ represents the expected number of pairs of items; $c$ is the number of items recalled on both trials; $h$ is the total number of items recalled on Recall 1 ; and $k$ is the total items recalled on Recall 2. Intertrial item pairings appeared with greater consistency in collaborative recall (mean $P F=0.69$ ) than in individual recall (mean $P F=0.08$ ). This difference was marginally significant, $t(62)=1.84, p=.07$, and suggests that the group maintained its organization better than individuals.

At first these results may seem inconsistent with the idea that collaborative inhibition is due to retrieval disruption (Basden et al., 1997). However, our organizational measure is based on a comparison across two recall trials, which uses the participants' first recalls as the standard of comparison, whereas Basden et al. (1997) examined organization within a single recall trial, with preexisting categories as the standard of comparison. Our data indicate that the organization of group recall is more consistent across trials, whereas Basden et al.'s data indicate that the groups are less organized within a single recall trial. Although counterintuitive, perhaps, these are not mutually exclusive outcomes. Groups may be disorganized when they first recall the material, but may better retain the organization that they establish. Group recall does not completely capture the individuals' representations of the material, but instead a new representation emerges through the group collaboration, which then is relatively stable over time. Thus, one important difference between collective and individual memories might be the relative stability of collective versus individual memories. Clearly, more research is needed to better understand how groups organize material and how they maintain that organization during group recall, but this finding suggests an interesting direction for future work.

Reciprocal effects of individual and group recall. A further question of interest concerned the effects of collaborative recall on individual recall, and vice versa. To assess this, performance on the second recall trial when preceded by individual recall was compared with performance on the second trial when preceded by group recall (see Table 1). For individuals, the second recall from II was compared with that from CI, and for collaborative groups, the second recall from IC was compared with that from CC. (The bold letter indicates the recall trial that was compared.) In individual recall, people recalled more if they had previously recalled with a group than if they had recalled alone, $F(1,94)=$ $31.94, M S E=0.030$. This is not surprising because, overall, the collaborative groups did recall more than single individu- als, so during collaborative recall each participant had a chance to hear items that he or she might have forgotten. Thus, people got a second study opportunity for more items when recalling collaboratively than when recalling alone, which boosted later individual performance.

The collaborative group showed a pattern different from that of individuals. Specifically, collaborative groups recalled somewhat more when recall was preceded by individual rather than by collaborative recall, but this trend was only marginally significant, $F(1,30)=3.26, M S E=0.025$, $p=.08$. Thus, for collaborative groups, prior collaborative recall did not appreciably improve memory relative to prior individual recall. Presumably this is because on the first recall trial, each person produced nearly all he or she could remember, and so members of the collaborative group heard only items that the group already remembered; there was no opportunity to relearn items the group did not remember.

\section{Discussion}

In summary, Experiment 1 revealed several interesting findings. First, although groups did recall more than individuals, there was an inhibitory effect of working in groups such that collaborative groups actually recalled less than nominal groups (pooled individuals). Paradoxically, whereas working in a group tended to help later recall by a single individual, it actually hurt the performance of the group as a whole. Not only did collaboration fail to optimize individual performance, it actually impaired individual performance (cf. Andersson \& Rönnberg, 1995, 1996; Meudell et al., $1992,1995)$. Although three heads may be better than one, three separate heads are better than three working together, at least with respect to the paradigm used here.

Second, collaborative recall exhibited some of the same phenomena as individual recall. Both groups and individuals exhibited a significant level-of-processing effect, a picturesuperiority effect, hypermnesia, and more reminiscence than forgetting. Thus, at least with respect to these variables, collaborative recall behaved like individual recall.

Third, there was evidence that collaborative recall may differ from individual recall in the stability of the representation over time. Groups exhibited somewhat less reminiscence and forgetting than individuals, and the groups' organization of the material was more consistent across recall trials. Thus, although the group output was not the sum of the individual recollections, it appears that a unique organization emerged during collaboration and that this organization was relatively stable over time.

Finally, individual recall benefited from prior collaborative recall. Presumably, group recall provided a second study opportunity for some items that the individual would not have recalled alone. However, collaborative recall did not reliably differ as a function of prior collaborative versus individual recall, so prior collaboration did not confer the same benefits to groups that it did to individuals.

\section{Experiment 2}

Experiment 2 was designed to see if the results of Experiment 1 generalized to recall of prose. Specifically, 
groups of 3 participants listened to the story "War of the Ghosts" (Bartlett, 1932) twice, and then tried to recall it either alone or collaboratively. The main goal was to see if the inhibitory effect of collaborative recall was also obtained with story recall.

It was possible that story recall would not exhibit the collaborative-inhibition effect observed with the free recall of unrelated word lists. First, recall of word lists might represent a relatively more artificial task for groups than for individuals. Individuals may be accustomed to recalling listlike information for tests in school, for example, but this rarely occurs as a group activity. In social interactions, it may be more common for groups to collaborate to remember stories and events, so groups may be relatively more skilled at this type of task.

Second, some investigators have hypothesized that people share common story grammars or normative story structures and schemata, which can be used to comprehend and recall stories (e.g., Bower, 1976; Kintsch \& van Dijk, 1978; Mandler \& Johnson, 1977; Thorndyke, 1977). Groups might be able to exploit these structures more effectively than individuals to facilitate story recall. For example, groups might be better able to collaboratively invoke a story structure, and this may help to cue recall of the elements of the story, or people working in a group might recall more total macropropositions (high-order conceptual units), which may also lead to recall of more micropropositions (loworder units; cf. Clark, Stephenson, \& Rutter, 1986). This is similar to Basden et al.'s (1997) suggestion that categorized lists should be less subject to collaborative inhibition because the structure imposed by the categories should help protect retrieval from the disruptive effects of group participation. Thus, the collaborative-group deficit might be eliminated when the material has a structure that the group members are likely to share and that they may be able to exploit more efficiently than individuals.

\section{Method}

Participants and design. One-hundred twenty undergraduates participated for credit in lower division psychology courses. None had participated in Experiment 1. Participants recalled the material twice, either individually (I) or collaboratively (C). There were two II conditions-one requiring oral recall (II-oral) and one requiring written recall (II-written)-to assess whether people who write the story produce less output than those who speak it. There were 24 people in each test condition: II-oral, II-written, IC, CI, and CC. Participants were randomly assigned to one of the five test conditions.

The comparison between oral and written recall was needed because people in the collaborative conditions recalled the story orally, but those in the individual conditions had to write their recalls because they were tested in groups of 3 and so could not say their individual recalls aloud. Because story recall requires considerable effort, it was possible that people who had to write their recalls (individual recall) would write less than those recalling orally (collaborative recall). Therefore, to try to assess the confound between recall modality (written vs. oral) and recall condition (individual vs. collaborative), both II-oral and II-written conditions were tested to see if people would produce less in the written condition. All participants in the II-oral condition were tested individually rather than in groups of 3.

Materials. The story "War of the Ghosts" was recorded by a man who worked at the campus radio station and had a clear voice. This reading was copied twice onto a cassette tape so that participants heard two identical readings in immediate succession.

Procedure. Participants were tested in groups of 3, except in the II-oral condition in which people were tested individually. In all conditions, people were told that they were participating in an experiment on problem solving. They were instructed to listen to the story carefully as it was read twice. Next, they worked on mazes individually for $5 \mathrm{~min}$ as a distractor task. They then received the recall instructions. In collaborative recall, participants were instructed to work together to recall the story as accurately as possible from beginning to end, telling the story aloud. They were given no instructions about bow to resolve discrepancies. The recall was videotaped. In the II-oral condition, participants received the same instructions except that they twice recalled the story aloud by themselves and they were videotaped. In all other individual recall conditions, participants received similar instructions except that they were told to write their recalls on a piece of blank paper. After the first recall, participants recalled the story again in the condition designated for their group (II-oral, II-written, $\mathrm{CC}, \mathrm{IC}$, or CI). In all conditions, participants were allowed up to 10 min for each recall, which was always more than adequate, and the recall trial was terminated when they reached the end of the story and indicated they were finished.

\section{Results}

The story was divided into the 42 propositional units suggested by Mandler and Johnson (1977; see Appendix). For the recalls, each unit was scored as wrong (0); partially correct (.5), meaning that part of the gist was correct; or correct (1), meaning that the whole gist was correct. Two judges scored each recall independently and then conferred to resolve any discrepancies. Initial interrater consistency was $90 \%$. Judges could not be kept unaware of the recall condition, because the videotapes revealed whether recall was collaborative or individual. As in Experiment 1, recalls were scored for the collaborative groups and for individuals, and the nominal-group data were derived from the individual data. Results are presented in Table 4 and Figure 3. In Experiment 2, we did not try to analyze intrusion rates because it would have been quite difficult to decide what

Table 4

Experiment 2: Proportion of Propositions Recalled From "War of the Ghosts"

\begin{tabular}{lccc}
\hline \multicolumn{1}{c}{ Recall condition } & $\begin{array}{c}\text { Individual } \\
\text { recall }\end{array}$ & $\begin{array}{c}\text { Nominal } \\
\text { group }\end{array}$ & $\begin{array}{c}\text { Collaborative } \\
\text { group }\end{array}$ \\
\hline $\begin{array}{l}\text { First recall } \\
\text { Second recall }\end{array}$ & .47 (II-oral) & .74 (II-oral) & $.59(\mathrm{CC})$ \\
$\begin{array}{c}\text { Preceded by indi- } \\
\text { vidual recall }\end{array}$ & .48 (II-oral) & .73 (II-oral) & $.52(\mathrm{IC})$ \\
$\begin{array}{c}\text { Preceded by col- } \\
\text { laborative recall }\end{array}$ & .57 (CI) & .74 (CI) & $.62(\mathrm{CC})$ \\
\hline
\end{tabular}

Note. The test conditions (in parentheses) indicate the source of the data, with the bold letter indicating the recall trial. II-oral = individual-individual, oral recall; $\mathrm{CC}=$ collaborative-collaborative; $\mathrm{IC}=$ individual-collaborative $\mathbf{C I}=$ collaborative-individual . 


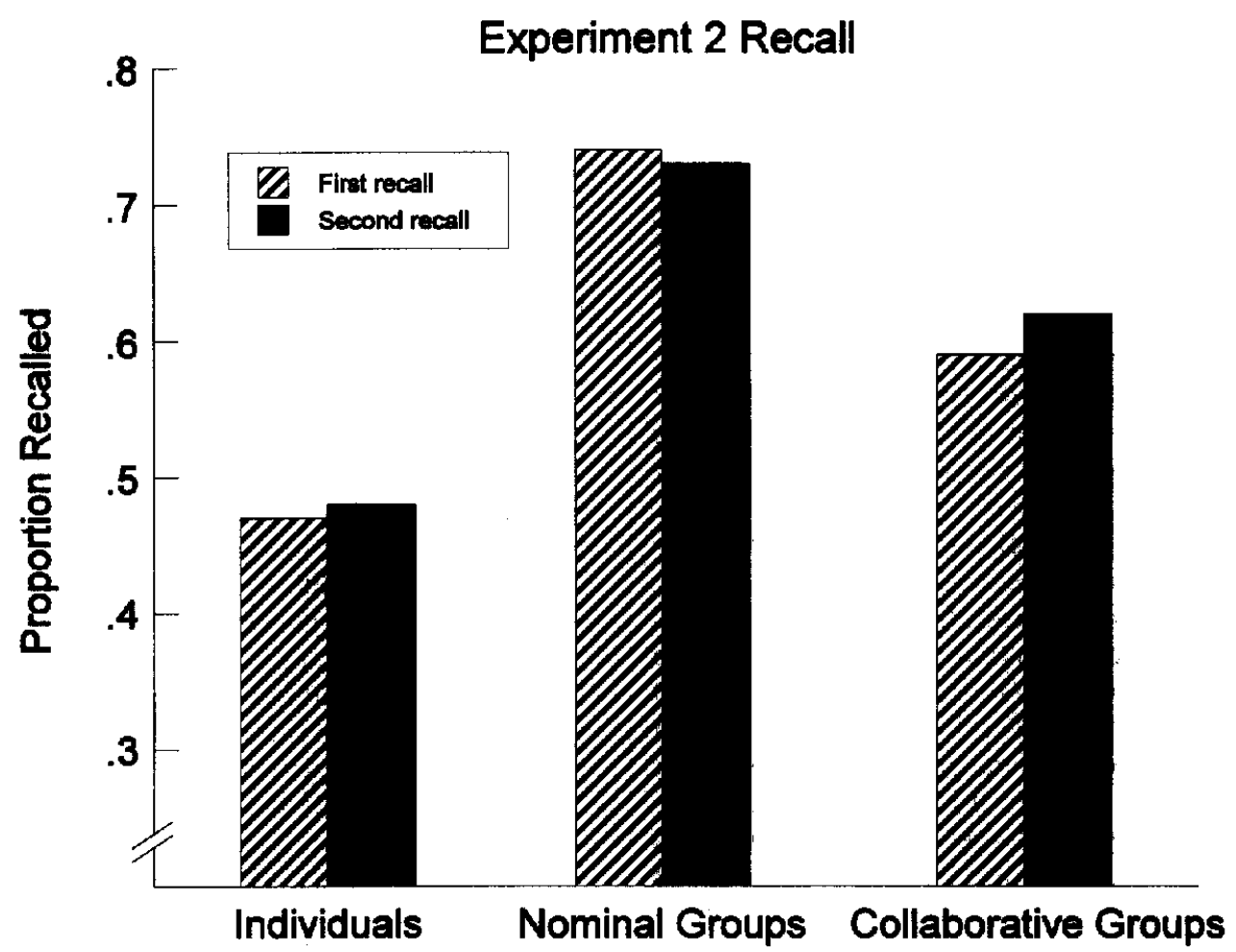

Figure 3. Recall on the first and second recall trials in Experiment 2. Data for the individuals and the nominal groups are from recall condition II. Data for the collaborative groups are from recall condition $\mathrm{CC}$. II = individual-individual; $\mathrm{CC}=$ collaborative-collaborative .

would count as an intrusion idea unit in story recall and to get high interrater reliability.

An ANOVA revealed that the proportions of correct recall did not differ in the II-oral $(M=.47)$ and II-written $(M=.51)$ conditions, $F(1,46)=1.24, M S E=0.022, p=.27$, and there was no interaction between recall modality and recall trial $(F<1)$. To prevent the number of observations in the individual versus group comparisons from becoming too unbalanced, the analyses were performed with the II-oral data, because this was most similar to the modality of recall in the groups.

Differences in productivity. Figure 3 compares proportion of correct recall on the first and second recall trials for individuals, nominal groups, and collaborative groups. Of most interest was the comparison between the nominal and collaborative groups. A 2 (group type: II-oral-nom vs. CC) $\times 2$ (recall trial: first vs. second) mixed ANOVA comparing the nominal and collaborative groups revealed a significant effect of recall condition, $F(1,14)=9.40$, $M S E=0.137$. Collaborative inhibition was obtained such that recall was worse in collaborative groups $(M=.60)$ than in nominal groups $(M=.73)$, replicating Experiment 1 . In this analysis, recall was not significantly better on the second recall trial than on the first $(F<1)$, and there was no significant interaction between group type and recall trial, $F(1,14)=1.30, M S E=0.003, p=.27$.

A 2 (group type: II-oral-ind vs. CC) $\times 2$ (recall trial: first vs. second) mixed ANOVA comparing individuals with collaborative groups revealed the expected finding that collaborative groups $(M=.60)$ recalled more than individuals $(M=.47), F(1,30)=9.81, M S E=0.020$. The trend toward better recall on the second trial was not significant, $F(1,30)=2.40, M S E=0.001, p=.13$, nor was the interaction between group type and recall trial, $F(1,30)=$ $2.84, M S E=0.001, p=.21$.

As in Experiment 1, to equate the number of observations in the $\Pi$ versus $C C$ comparison, the average performance of the best individuals from each II-oral group was compared with the average performance of the collaborative groups. In contrast to Experiment 1, however, there was no difference between the best individuals $(M=.56)$ and the collaborative groups $(M=.60), t(14)<1$. We also compared the mean of the best individuals in written recall $(M=.60)$, and this also was not different from the collaborative group, $t(14)<1$. Thus, these data suggest that with story recall, the performance of the best individual may be close to the upper bound of performance in the collaborative group. These data contrast with Experiment 1, in which the collaborating groups' performance was significantly better than that of the best individuals. There may have been a difference in how groups collaborated when recalling lists of unrelated words versus stories. Perhaps with stories, the groups tended to rely on the person who appeared to recall the most.

To examine the hypothesis that collaborative groups relied on the best individual in Experiment 2 but not in Experiment 1, several analyses were conducted. We exam- 
ined the data in the IC conditions to see whether the best individual's performance on Recall 1 appeared to predict the collaborating group's performance on Recall 2. First, we correlated the number of items recalled by the best individual with the number recalled by the collaborating group. In Experiment 1, $r=.31, p=.31$, whereas in Experiment 2, $r=.71, p=.05$, indicating that the level of recall in the groups was more highly correlated with the best individual during story recall than list recall.

In another approach, we looked at item additions, defined as the number of items the group recalled during Recall 2 that were not recalled by the best individual on Recall 1 . In this analysis, if the group was simply following the best individual, they should not have added many additional items. Before conducting this analysis, we had to correct for differences in the levels of the best individuals' performances on Recall 1. For example, if the best individual recalled 30 of the 40 items, then only 10 items remained to be added, whereas if the best individual recalled 20 of the 40 items, then 20 items remained. Therefore, we computed item additions as the number of items the group added to the best individual, divided by the number of items unrecalled by the best individual. For example, in Experiment 1, which had 40 targets, if the best individual recalled 22 items and the group added 4 items, then additions $=4 /(40-22)=0.22$. In Experiment 2, the computation allowed for a maximum of 42 items. Consistent with expectations, the proportion of items added by the collaborative group in Experiment 2 for story recall $(M=.26)$ was slightly less than in Experiment 1 for list recall $(M=.31)$, but the difference was not significant, $t(22)=1.16, p=.26$. Of course, the power of this cross-experiment comparison is low because there were only 16 groups in Experiment 1 and 8 in Experiment 2.

Finally, we viewed the tapes of the group recalls and selected the person who appeared to be the group leader or who appeared to dominate recall, then compared this with the person who had the best recall in the individual recall session. In six out of eight cases they were the same person. In the videotapes of story recall in Experiment 2, there was a tendency in many groups for the participants to let one person take charge, while the others monitored his or her performance, occasionally adding an addition or correction. Because we do not have videotapes of the list recalls from Experiment 1, however, we could not do a cross-experiment comparison of the role of the individual with the best recall.

In summary, then, there is some evidence that the collaborative groups tended to rely on the best individual to a greater extent during story recall than during list recall, but this evidence requires further verification. Implications are addressed in the General Discussion.

Hypermnesia, reminiscence, and forgetting. As mentioned earlier, in the analysis comparing individuals with collaborative groups, the trend toward hypermnesia was not significant. Nevertheless, we examined interest reminiscence and forgetting for the story propositions, and the mean numbers of items recovered and forgotten across the two recall trials are presented in Table 5. A $2 \times 2$ mixed ANOVA was conducted on recall condition (individual-oral vs. collaborative) and item status (reminiscence vs. forgetting).
Table 5

Experiment 2: Intertest Reminiscence and Forgetting, Expressed as Number of Items

\begin{tabular}{lccc}
\hline $\begin{array}{c}\text { Intertest } \\
\text { performance }\end{array}$ & $\begin{array}{c}\text { Individual recall } \\
\text { (II-oral) }\end{array}$ & $\begin{array}{c}\text { Nominal } \\
\text { (II-oral) }\end{array}$ & $\begin{array}{c}\text { Collaborative } \\
\text { group (CC) }\end{array}$ \\
\hline Reminiscence & 3.23 & 2.06 & 4.50 \\
Forgetting & 2.75 & 2.31 & 3.06 \\
\hline
\end{tabular}

Note. $\quad$ II-oral $=$ individual-individual recall condition, oral recall; $\mathrm{CC}=$ collaborative-collaborative recall condition .

As in Experiment 1, there was somewhat more reminiscence than forgetting, although here the effect was only marginally significant, $F(1,30)=11.02, M S E=2.99, p=.06$, which accounts for the lack of significant hypermnesia. Neither the effect of recall condition, $F<2.31, M S E=3.25, p=.14$, nor the interaction between recall condition and item status $(F<1)$ was significant.

These data differed from those in Experiment 1 in that the hypermnesia was not significant here. Wheeler and Roediger (1992) did obtain hypermnesia when individuals recalled "War of the Ghosts" twice, although the effect was quite small, with just one additional idea unit recalled on the second trial. However, we were not specifically looking for hypermnesia and did not give the typical instructions to obtain hypermnesia, so we are unconcerned about this aspect of the data for now.

Subjective organization. With these materials, we were able to evaluate two aspects of the organization of the material. First, to examine whether collaboration disrupted individual organization, we compared the organization of the first and second story recalls with the original story by computing Spearman rank-order correlations between the order of the propositions in recall and in the original story. These correlations were computed for each individual (II) and for each collaborative group (CC). The average correlation was .99 in all four conditions (both the individuals and the groups on both the first and the second recalls). Although the correlations were too high to enable a meaningful statistical analysis, they do suggest that even though groups recalled fewer actual propositions than the pooled individuals, what they did recall was highly organized relative to the original story.

Second, we examined whether groups maintained the organization of the material over time better than individuals, as was suggested in Experiment 1 . We computed the rank-order correlations between the first and second recalls of the individuals and groups, and the average correlations for the groups and the individuals were both .98. Thus, both groups and individuals exhibited very high stability, but again the ceiling effect makes the numbers difficult to interpret because it obscures any potential difference.

The highly organized recall seen in the rank-order correlations may be attributable to the nature of the material. Story recall is very constrained because story grammar demands coherence and restricts the order in which the propositions can be recalled, particularly in a brief story. There was little room for much variance in this measure. Therefore, these data were not helpful in determining whether, in general, 
groups experience more initial retrieval disruption or maintain a more stable organization than individuals.

Reciprocal effects of individual and group recall. To assess the effects of prior recall on later recall, data for the second recall trials were analyzed for individuals (CI, II-written, II-oral) and collaborative groups (IC, CC). (The II-written data were evaluated here because they were more similar to the CI condition, in which all the group members wrote their individual recalls.) The individual recall data replicated Experiment 1 in that individual recall was better when preceded by collaborative than individual recall. The difference between the second recalls of the CI $(M=.57)$ and II-written $(M=.51)$ conditions was just significant, $F(1,46)=3.85, M S E=0.012, p=.056$, and the difference between the second recalls of the CI and II-oral $(M=.48)$ conditions was significant, $F(1,46)=7.84, M S E=0.013$. Again, it appears that group recall provided a second study opportunity for some items the individuals had forgotten.

The results for the collaborative groups contrasted with those from Experiment 1. Here, collaborative recall was significantly better following collaborative recall (for $\mathrm{CC}$, $M=.62$ ) than following individual recall (for IC, $M=.52$ ), $F(1,14)=4.90, M S E=0.008$. This finding was not predicted. However, it is consistent with the possibility that groups may have tended to conform to the best individual in story recall. That is, because the best individual had an opportunity to relearn more of the story during collaborative than individual recall, the upper bound on performance in the second recall, which tended to be set by the best individual, would have tended to be higher after a collaborative first recall. However, one problematic aspect of these data is that the second recall in the IC condition $(M=.52)$ was actually worse than the first recall in the CC condition $(M=.59)$, so second recall in the IC condition might have been artificially low, rather than second recall in the CC $(M=.62)$ condition being relatively improved. Therefore, additional work is needed to determine whether the benefit of collaborative recall for stories is a replicable result.

\section{Discussion}

In summary, the data of most interest replicate the findings of Experiment 1. Although collaborative groups did recall more than individuals working alone, they actually recalled less than pooled individuals. Using a story rather than an unrelated list of items did not eliminate this collaborative inhibition. In fact, if anything, the collaborativegroup deficit appeared even larger with the story. Simply sharing knowledge of story structure did not enhance the collaborative groups' performance. Although this shared story grammar may have contributed to the very high correlation between the organization of the groups' recalls and the original story, it did not enable the group to recall enough propositions to overcome collaborative inhibition. Again, collaboration did not optimize individual performance. Somewhat paradoxically, however, individual recall ultimately benefited from collaborative recall in both experiments, a result consistent with other findings in the literature (e.g., Stephenson \& Wagner, 1989). The effect presumably reflects the opportunity for individuals to be reexposed to items they did not recall on the first recall trial, thereby making them more accessible for later retrieval.

Story recall also exhibited some differences from list recall. First, with the story there was some evidence that the groups tended to rely on the best individual, which set a relatively low upper bound on the amount of material the group recalled, relative to what each individual actually knew. This was not the case with list recall, in which the group recalled significantly more than the best individual. We can only speculate on what might have underlain this difference, but two factors might have been at work. First, different social norms might govern story versus list recall, such that people may have felt reluctant to interrupt someone telling a story. Second, stories are relatively coherent, whereas random lists are relatively disjointed. Thus, it might have been easier for individuals to add additional items during list recall because recall order was unconstrained, and it would have been less disruptive to interject any items that came to mind.

A second difference between list and story recall was that with list recall the groups' performance tended to be more stable than the individuals', but with story recall both the groups and individuals exhibited very high stability and conformed closely to the original story order.

Finally, the effects of prior recall on collaborative recall were somewhat different in the two experiments. Experiment 1 indicated that collaborative recall was about the same when preceded by individual and collaborative recall, but Experiment 2 suggested that collaborative recall was better following collaborative recall. It is possible that for collaborative groups the effect of prior recall depended on the type of material to be remembered (e.g., unrelated item lists vs. stories). If groups relied on the best individual more in story recall than in random-list recall, the effects of prior collaborative recall may have been different in each case, as suggested earlier.

\section{General Discussion}

Two experiments were conducted to compare individual and collaborative recall. In Experiment 1, participants studied random lists of pictures and words with either a deep or a shallow encoding task. In Experiment 2, participants heard the story "War of the Ghosts." In each experiment people recalled the material twice in one of four conditions representing combinations of individual and collaborative recall (II, CC, IC, or CI). Performance was compared for individuals, collaborative groups, and nominal groups constructed by pooling the nonredundant answers of individuals.

As expected, collaborative groups recalled more than individuals. However, the most interesting outcome in both experiments was that collaborative groups recalled less than nominal groups. Thus, although collaboration was better than individual recall, collaboration did not optimize individual performance. An inhibitory process appears to operate in collaborative recall, producing collaborative inhibition. These data are consistent with Lorge and Solomon's (1961) finding that a model predicting additivity of indi- 
vidual performance overpredicted group performance on a multitrial learning task (cf. Andersson \& Rönnberg, 1995, 1996; Hoppe, 1962).

Similar effects have been reported in other domains. In brainstorming, nominal groups produce a greater number of unique ideas than do collaborative groups (e.g., Bouchard \& Hare, 1970; Diehl \& Stroebe, 1987; Dunnette, Campbell, \& Jaastad, 1963; Taylor et al., 1958). Also, in emergency situations, a person alone is more inclined to help than is a person in a group, and the probability of lending assistance decreases as group size increases (Darley \& Latané, 1968). In many other tasks, from rope pulling to vigilance tasks, people contribute less when working in groups than when working alone (see review by Karau \& Williams, 1993).

A variety of mechanisms have been proposed to explain the loss of individual productivity in group work. Many of these mechanisms focus on motivational factors, and these conceivably could be at play in collaborative recall. One proposed explanation is free riding or social loafing, the idea that people do not work as hard in groups as they do when working alone. Social loafing may occur because in group work (a) personal accountability is diminished, making it easier to exert less effort without being noticed; (b) there is perceived dispensibility of effort, or the perception that one's contribution will not make much of a difference; (c) individuals attempt to achieve an equity of effort, but performance will be low because each person's output is initially limited by having to allow others to take their turns; and (d) there is a diffusion of responsibility, or a belief that one is less accountable for the group's behavior than for one's individual behavior (Latané \& Nida, 1981). There is some evidence that free riding plays a small role in productivity loss in brainstorming groups (e.g., Diehl \& Stroebe, 1987; Harkins \& Petty, 1982), but it does not appear to account for the whole effect. Finally, evaluation apprehension might inhibit individual contributions if one is concerned about being evaluated negatively by the group (e.g., Collaros \& Anderson, 1969; Diehl \& Stroebe, 1987).

A second major hypothesized source of collaborative inhibition in cognitive tasks is production blocking (Diehl \& Stroebe, 1987; Lamm \& Trommsdorff, 1973), or the idea that because only one group member can speak at a time, individuals cannot produce all the ideas that they would otherwise. The exact mechanism through which this might inhibit individual performance is unclear, but possibilities include that (a) one needs to remember one's own ideas while waiting for others, and this interferes with one's ability to generate new ideas; (b) one might forget one's own ideas while waiting for others; (c) as others present their ideas, one might see one's own as less valuable or original and so suppress them; (d) one might be distracted by listening to others, which might disrupt one's own thought processes. Diehl and Stroebe (1987) have argued that production blocking accounts for most of the group-productivity loss in brainstorming. Any of these processes could theoretically operate in collaborative recall.

In line with this idea, production blocking during collaborative recall could occur through a process similar to that which underlies part-list cuing and retrieval-inhibition ef- fects (e.g., Basden \& Basden, 1995; Roediger \& Neely, 1982; Slamecka, 1969). In the part-list cuing effect, during retrieval some people are shown a subset of the target words and are asked to recall the remaining words. Recall for the remaining words is actually worse than when people are given no subset of target words during recall. This inhibitory effect has been attributed to various mechanisms (see reviews by Nickerson, 1984; Roediger, 1973; Rundus, 1973). For example, the retrievability of the presented targets might be strengthened, to the detriment of the remaining subset. Alternatively, Basden and Basden (1995) have proposed that the intralist cues disrupt the individual's organization of the material, thereby impairing recall.

Our experiments do not provide much direct evidence to distinguish between motivational and cognitive causes of the collaborative-inhibition effect. However, some aspects of the data suggest that both motivational factors and cognitive factors are at work. For example, collaborative inhibition appeared to be somewhat larger in Experiment 2 than in Experiment 1, indicating that people did not contribute as much of their individual knowledge to the group with story recall as they did with list recall. Also, there was evidence that groups tended to follow the best individual to a greater extent in story recall than in random-list recall. These findings suggest a possible role of motivational factors, in that story recall might be perceived as more difficult, and so individuals might be more willing to defer to others in the group. In addition, social norms may make people more reluctant to interrupt someone telling a story. These findings also suggest a role for cognitive factors. Because the organizational structure of a story is relatively complex and rigid, it may take considerable cognitive effort to retrieve and maintain one's own representation while monitoring the story development in the group. Furthermore, an individual may not want to slow down the pace of the group story reconstruction, so rather than asking the group to pause while one tries to retrieve more details, a person might contribute only items that he or she can retrieve easily and quickly. In contrast, in list recall there is no obvious order in which the material must be retrieved, and pauses in the recall become frequent and long, so the individual members can spend more time and effort retrieving items without appearing to disrupt the group activity. Thus, both social and cognitive factors may interact to inhibit individual performance in collaborative recall, but the severity of this inhibition may be modulated by the type of material.

More direct evidence for the role of cognitive factors in collaborative inhibition was provided by Basden et al. (1997), who examined group recall for categorized lists. Such lists seem to provide a middle ground between the random word list and the organized story, and provide a better opportunity for assessing the organization of recall relative to the original material. Basden et al. demonstrated that group recall conforms less well to the organizational structure of the categorized lists than does individual recall, thus supporting the idea that retrieval disruption may play a role in collaborative inhibition.

The idea that cognitive inhibition arises from retrieval interference suggests some additional avenues for future 
research. If one can find situations in which collaboration does not interfere with individual organization, collaboration should not inhibit recall. Thus, one strategy would be to examine collaborative recall for material that is likely to be organized very similarly by the members of the group, such as highly structured material (although our Experiment 2 suggests this material should also be relatively easy to recall). Another factor that may reduce retrieval interference is familiarity among group members. For example, individuals in long-term intimate or working relationships may be able to coordinate their recall better than do groups of strangers, and may thereby reduce interference. Finally, it is possible that domains in which the information is richly interconnected may be more resistant to collaborative inhibition. For example, in a variety of semantic-memory tasks, such as answering trivia questions or reconstructing a map of the United States (both of which we are currently testing), there may be a sufficient variety of retrieval routes so that the potential of cross-cuing overrides the decrement produced by interference. Evidence that collaborative inhibition may be reduced in semantic memory tests and when collaborating with friends has recently been obtained by Andersson and Rönnberg $(1995,1996)$ in studies of dyad recall.

Experiment 1 did provide interesting information about possible differences in the representation of information in groups versus individuals. The intertrial organization of the material was somewhat higher for groups than for individuals, suggesting that although groups do not manage to incorporate all of the individuals' knowledge, they do create a new organization of the material that is relatively more stable over time. In future work, it will be useful to see if this finding holds for other types of materials and to develop paradigms to determine whether the groups' representations have emergent properties that cannot be predicted from the individuals' representations.

Our findings are consistent with those of Meudell and colleagues (Meudell et al., 1992, 1995), in the sense that their findings also failed to show any advantage of collaboration relative to pooled individual performance. However, they tested dyads and found no difference between nominal and collaborative groups, whereas we tested triads and found inhibition in the collaborative groups. Thus, dyads appear to exhibit additivity, but larger groups actually inhibit recall (but see Andersson \& Rönnberg, 1995, 1996, who obtained evidence for collaborative inhibition in dyads). This finding suggests that relative inhibition may increase as group size increases, a hypothesis that should be examined in future work. The difference between dyads and triads is also consistent with the possibility that collaborative inhibition results from retrieval disruption, because more disruption would occur with larger groups. On the other hand, it is possible that dyads represent a social group with unique properties, as suggested by the fact that the dyads can exhibit no collaborative inhibition, even though a partner's recall should produce interference. However, Meudell et al.'s $(1992,1995)$ participants recalled the material as individuals before recalling it as pairs, which may have served to consolidate the information and make it resistant to interference by the other person. Clearly, the difference between dyads and larger groups represents an interesting area for further work, and may be helpful in assessing the cognitive and social contributions to collaborative inhibition.

In conclusion, the present work demonstrated the importance of social factors in cognitive performance, factors which historically have been ignored in experimental cognitive psychology. Here it was shown that groups exhibit some of the same phenomena as individuals (i.e., the level-ofprocessing effect, picture-superiority effect, and hypermnesia), but collaboration did not optimize the performance of individuals. Whereas one might predict that collaborative recall should enhance individual recall by providing additional retrieval cues, in fact collaboration actually inhibited individual performance. Future work should be directed toward understanding the possible roles of cognitive and motivational factors in producing this effect, and toward developing theoretical frameworks that account for the interplay between individual and collaborative memory processes. More broadly, as discussed in the introduction, memory can be considered to be social in many different ways, and investigations of these dimensions promise to enrich our understanding of mnemonic processes.

\section{References}

Anderson, R. C., \& Watts, G. H. (1969). Bidirectional associations in multi-trial free recall. Psychonomic Science, 15, 288-289.

Andersson, J., \& Rönnberg, J. (1995). Recall suffers from collaboration: Joint recall effects of friendship and task complexity. Applied Cognitive Psychology, 9, 199-211.

Andersson, J., \& Rönnberg, J. (1996). Collaboration and memory: Effects of dyadic retrieval on different memory tasks. Applied Cognitive Psychology, 10, 171-181.

Bartlett, F. C. (1932). Remembering: A study in experimental and social psychology. Cambridge, England: Cambridge University Press.

Basden, B. H., Basden, D. R., Bryner, S., \& Thomas, R. L,, III. (1997). A comparison of group and individual remembering: Does group participation disrupt retrieval? Journal of Experimental Psychology: Learning. Memory, and Cognition, 23, 11761189.

Basden, D. R., \& Basden, B. H. (1995). Some tests of the strategy disruption interpretation of part-list cuing inhibition. Journal of Experimental Psychology: Learning, Memory, and Cognition, $21,1656-1669$.

Bouchard, T. J., Jr., \& Hare, M. (1970). Size, performance, and potential in brainstorming groups. Joumal of Applied Psychology, 54, 51-55.

Bower, G. H. (1976). Experiments on story understanding and recall. Quarterly Journal of Experimental Psychology, 28, 511-534.

Clark, N. K., \& Stephenson, G. M. (1989). Group remembering. In P. B. Paulus (Ed.), Psychology of group influence (2nd ed., pp. 357-391). Hillsdale, NJ: Erlbaum.

Clark, N. K., Stephenson, G. M., \& Kniveton, B. (1990). Social remembering: Quantitative aspects of individual and collaborative remembering by police officers and students. British Journal of Psychology, 81, 73-94.

Clark, N. K., Stephenson, G. M., \& Rutter, D. R. (1986). Memory for a complex social discourse: The analysis and prediction of individual and group recall. Journal of Memory and Language, 25, 295-313.

Collaros, P. A., \& Anderson, L. R. (1969). Effect of perceived expertness upon creativity of members of brainstorming groups. Journal of Applied Psychology, 53, 159-163. 
Craik, F. 1. M., \& Lockhart, R. S. (1972). Levels of processing: A framework for memory research. Journal of Verbal Learning and Verbal Behavior, 11, 671-684.

Craik, F. I. M., \& Tulving, E. (1975). Depth of processing and the retention of words in episodic memory. Journal of Experimental Psychology: General, 104, 268-294.

D'Agostino, P. R., O’Neill, B. J., \& Paivio, A. (1977). Memory for pictures and words as a function of level of processing: Depth or dual coding? Memory \& Cognition, 5, 252-256.

Darley, J. M., \& Latane, B. (1968). Bystander intervention in emergencies: Diffusion of responsibility. Journal of Personality and Social Psychology, 8, 377-388.

Dashiell, J. F. (1935). Experimental studies of the influence of social situations on the behavior of individual human adults. In C. Murchison (Ed.), A handbook of social psychology (Vol. 2, pp. 1097-1158). New York: Russell \& Russell.

Diehl, M., \& Stroebe, W. (1987). Productivity loss in brainstorming groups: Toward the solution of a riddle. Joumal of Personality and Social Psychology, 53, 497-509.

Dunnette, M. D., Campbell, J., \& Jaastad, K. (1963). The effects of group participation on brainstorming effectiveness for two industrial samples. Journal of Applied Psychology, 47, 30-37.

Durkheim, E. (1915). Elementary forms of the religious life. New York: Macmillan.

Durso, F. T., \& Johnson, M. K. (1980). The effects of orienting tasks on recognition, recall, and modality confusion of pictures and words. Joumal of Verbal Learning and Verbal Behavior, 19, $416-429$.

Erdelyi, M. H., \& Kleinbard, J. (1978). Has Ebbinghaus decayed with time? The growth of recall (hypermnesia) over days. Joumal of Experimental Psychology: Human Leaming and Memory, 4, 275-289.

Halbwachs, M. (1980). The collective memory. (F. J. Ditter, Jr. \& V. Y. Ditter, Trans.). New York: Harper \& Row. (Original work published 1950)

Harkins, S. G., \& Petty, R. E. (1982). Effects of task difficulty and task uniqueness on social loafing. Journal of Personality and Social Psychology, 43, 1214-1229.

Hoppe, R. A. (1962). Memorizing by individuals and groups: A test of the pooling-of-ability model. Journal of Abnormal and Social Psychology, 65, 64-67.

Jung, C. G. (1953). The collected works of C. G. Jung (H. Read, M. Fordham, \& G. Adler, Eds.). New York: Pantheon Books.

Karau, S. J., \& Williams, K. D. (1993). Social loafing: A meta-analytic review and theoretical integration. Journal of Personality and Social Psychology, 65, 681-706.

Kintsch, W., \& van Dijk, T. A. (1978). Towards a model of text comprehension and production. Psychological Review, 85, 363394.

Lamm, H., \& Trommsdorff, G. (1973). Group versus individual performance on tasks requiring ideational proficiency (brainstorming). European Journal of Social Psychology, 3, 361-387.

Latane, B., \& Nida, S. A. (1981). Ten years of research on group size and helping. Psychological Bulletin, 89, 308-324.

Lorge, I., \& Solomon, H. (1961). Group and individual behavior in free recall. In J. H. Criswell, H. Solomon, \& P. Suppes (Eds.), Mathematical methods in small group processes (pp. 221-231). Stanford, CA: Stanford University Press.

Mandler, J. M., \& Johnson, N. S. (1977). Remembrance of things parsed: Story structure and recall. Cognitive Psychology, 9, 111-151.

Meudell, P. R., Hitch, G. J., \& Boyle, M. M. (1995). Collaboration in recall: Do pairs of people cross-cue each other to produce new memories? Quarterly Journal of Experimental Psychology: Human Experimental Psychology, 48(A), 141-152.
Meudell, P. R., Hitch, G. J., \& Kirby, P. (1992). Are two heads better than one? Experimental investigations of the social facilitation of memory. Applied Cognitive Psychology, 6, 525-543.

Nelson, D. L. (1979). Remembering pictures and words: Appearance, significance, and name. In L. S. Cermak \& F. I. M. Craik (Eds.), Levels of processing in human memory (pp. 45-76). Hillsdale, NJ: Erlbaum.

Nickerson, R. S. (1984). Retrieval inhibition from part-set cuing: A persisting enigma in memory research. Memory \& Cognition, 12, 531-552.

Paivio, A. (1971). Imagery and verbal processes. New York: Holt, Rinehart \& Winston.

Payne, D. G. (1986). Hypermnesia for pictures and words: Testing the recall level hypothesis. Journal of Experimental Psychology: Learning, Memory, and Cognition, 12, 16-29.

Payne, D. G. (1987). Hypermnesia and reminiscence in recall: A historical and empirical review. Psychological Bulletin, 101, 5-27.

Ravicchio, D., Thomas, R. L., III, Randall, W., Souphasith, S., Speer, M., Basden, B. H., \& Basden, D. R. (1996, May). False remembering in group recall and recognition. Poster session presented at the Eighth Annual Convention of the American Psychological Society, San Francisco, CA.

Roediger, H. L., III. (1973). Inhibition in recall from cueing with recall targets. Journal of Verbal Learning and Verbal Behavior, $12,644-657$.

Roediger, H. L., III, \& Neely, J. H. (1982). Retrieval blocks in episodic and semantic memory. Canadian Journal of Psychol$o g y, 36,213-242$.

Rogoff, B., \& Mistry, J. J. (1985). Memory development in cultural context. In M. Pressley \& C. Brainerd (Eds.), Cognitive learning and memory in children (pp. 117-142). New York: SpringerVerlag.

Rundus, D. (1973). Negative effects of using list items as recall cues. Journal of Verbal Learning and Verbal Behavior, 12, 43-50.

Slamecka, N. J. (1969). Testing for associative storage in multitrial free recall. Journal of Experimental Psychology, 81, 557-560.

Snodgrass, J. G., \& Vanderwart, M. (1980). A standardized set of 260 pictures: Norms for name agreement, image agreement, familiarity, and visual complexity. Journal of Experimental Psychology: Human Learning and Memory, 6, 174-215.

Stephenson, G. M., Brandstätter, H., \& Wagner, W. (1983). An experimental study of social performance and delay on the testimonial validity of story recall. European Journal of Social Psychology, 13, 175-191.

Stephenson, G. M., \& Wagner, W. (1989). Origins of the misplaced confidence effect in collaborative recall. Applied Cognitive Psychology, 3, 227-236.

Sternberg, R. J., \& Tulving, E. (1977). The measurement of subjective organization in free recall. Psychological Bulletin, 84 , 539-556.

Taylor, D. W., Berry, P. C., \& Block, C. H. (1958). Does group participation when using brainstorming facilitate or inhibit creative thinking? Administrative Science Quarterly, 3, 23-47.

Thorndyke, P. (1977). Cognitive psychology. Cognitive Structures in Comprehension and Memory of Narrative Discourse, 9, 77-110.

Vollrath, D. A., Sheppard, B. H., Hinsz, V. B., \& Davis, J. H. (1989). Memory performance by decision-making groups and individuals. Organizational Behavior and Human Decision Processes, 43, 289-300.

Vygotsky, L. S. (1962). Thought and language. Cambridge, MA: Harvard University Press.

Vygotsky, L. S. (1978). Mind in society. Cambridge, MA: Harvard University Press.

Wegner, D. M., Giuliano, T., \& Hertel, P. T. (1985). Cognitive 
interdependence in close relationships. In W. Ickes (Ed.), Compatible and incompatible relationships (pp. 253-276). New York: Springer-Verlag.

Weldon, M. S., \& Coyote, K. C. (1996). Failure to find the picture superiority effect in implicit conceptual memory tests. Journal of Experimental Psychology: Learning, Memory, and Cognition, $22,670-686$.
Wheeler, M. A., \& Roediger, H. L., III. (1992). Disparate effects of repeated testing: Reconciling Ballard's (1913) and Bartlett's (1932) results. Psychological Science, 3, 240-245.

Wundt, W. (1916). Elements of folk psychology (E. L. Schaub, Trans.). New York: Macmillan. (Original work published 1910)

Yuker, H. E. (1955). Group atmosphere and memory. Journal of Abnormal and Social Psychology, 51, 117-123.

\section{Appendix}

\section{Idea Units for Scoring "War of the Ghosts," Taken From Mandler and Johnson (1977)"}

1. One night two young men from Egulac went down to the river to hunt seals,

2. and while they were there it became foggy and calm.

3. Then they heard war cries,

4. and they thought, "Maybe this is a war party."

5. They escaped to the shore

6. and hid behind a log.

7. Now canoes came up,

8. and they heard the noise of paddles

9. and saw one canoe coming up to them.

10. There were five men in the canoe,

11. and they said, "What do you think? We wish to take you along.

12. We are going up the river to make war on the people."

13. One of the young men said, "I have no arrows."

14. "Arrows are in the canoe," they said.

15. "I will not go along.

16. I might be killed.

17. My relatives do not know where I have gone.

18. But you," he said, turning to the other, "may go with them."

19. So one of the young men went,

20. but the other returned home.

21. And the warriors went up the river to a town on the other side of Kalama.

22. The people came down to the water,

23. and they began to fight,

24. and many were killed.

25. But presently the young man heard one of the warriors say, "Quick, let us go home; that Indian has been hit."
26. Now he thought, "Oh, they are ghosts."

27. He did not feel sick,

28. but they said he had been shot.

29. So the canoes went back to Egulac,

30. and the young man went ashore to his house and made a fire.

31. And he told everybody and said, "Behold, I accompanied the ghosts, and we went to a fight.

32. Many of our fellows were killed,

33. and many of those who attacked us were killed.

34. And they said I was hit

35. and I did not feel sick."

36. He told it all,

37. and then he became quiet.

38. When the sun rose he fell down.

39. Something black came out of his mouth.

40. His face became contorted.

41. The people jumped up and cried.

42. He was dead.

${ }^{1}$ From "Remembrance of Things Parsed: Story Structure and Recall," by J. M. Mandler and N. S. Johnson, 1977, Cognitive Psychology, 9, p. 136. Copyright 1977 by Academic Press. Reprinted with permission.

Received July 10, 1995

Revision received February 27, 1997

Accepted February 28, 1997 